\title{
Studi Pemenuhan Air Baku Dengan Metode Penurapan Dan PAH Oleh Masyarakat Pulau Palue-NTT
}

\author{
Mauritius I. R. Naikofi ${ }^{\# 1}$, Egidius Kalogo ${ }^{* 2}$, Sebastianus B. Henong ${ }^{* 2}$, Paulus Sianto ${ }^{* 2}$, \\ F.Wahyu Kristono ${ }^{\# 3}$ \\ ${ }^{\# 1}$ Jurusan Teknik Sipil Universitas Katolik Widya Mandira \\ ${ }^{* 2}$ Jurusan Teknik Sipil Universitas Katolik Widya Mandira \\ \#3 Staf Ahli Teknik Konsultan Kencana Layana Group \\ ${ }^{1}$ mauritiusnaikofi@yahoo.co.id \\ 2egidius.kalogo@yahoo \\ 33wahyukristono@gmail.com
}

\begin{abstract}
The program to meet the needs of Raw Water for the domestic needs of the community, especially drinking water and other household needs, is very intensively carried out by the provincial government of East Nusa Tenggara. The difficulty faced is that efforts to equalize the fulfillment of the need for clean water in the archipelago require quite expensive costs and technology. Palue Island in Sikka Regency is one of the islands of hundreds of regions experiencing a clean water crisis. Fulfillment of consumption water needs only comes from the results of the Steam Water Condensation using plaster and PAH methods. This research was conducted to determine the feasibility and contribution of the fulfillment of residents' raw water by the anointing method that has been carried out by the Palue Island people for generations.
\end{abstract}

Keywords: Raw Water, Islands Region, Turap Method, Palue Island Community.

\section{PENDAHULUAN}

Pulau Palue secara administrasi termasuk dalam wilayah kabupaten Sikka Provinsi Nusa Tenggara Timur. Kecamatan Palue (Pulau Palue) dengan luas wilayah $40 \mathrm{~km}^{2}$ memiliki \pm 10.000 jiwa yang tersebar di 8 (delapan) desa. Pendapatan utama desa hanya dari sector pertanian dengan komoditi utamanya adalah mente, jagung, palawija dan hasil kebun lainnya. Sedangkan hasil laut hanya untuk konsumsi dalam rumah tangga.

Hal dasar pemenuhan kebutuhan air konsumsi dan kebutuhan air untuk keperluan rumah tangga lainnya merupakan masalah pokok yang di alami masyarakat pulau palue secara turun temurun. Satu-satunya sumber air baku yang ada saat ini yaitu pengambilan air dengan Metode Penurapan (pengambilan air lewat proses kondensasi dengan pipa bambu) dan PAH (Penampungan Air Hujan). Sedangkan kebutuhan MCK (Mandi Cuci Kakus) menggunakan air sumur yang hanya berjumlah 9 buah dan tersebar dalam 3 Desa, sehingga masalah kesehatan juga menjadi perhatian.

Kegiatan ini dilakukan untuk mengetahui proses dan pemenuhan air baku masyarakat di Pulau Palue.

\section{METODE KERJA}

\section{Identifikasi Masalah}

Identifikasi dilakukan dengan metode survey lapangan dengan pemilihan metode survey Hidrometri dan pengumpulan data sosial ekonomi masyarakat dan pengumpulan literatur pendukung lainnya. 


\section{Orientasi Kegiatan}

Orientasi dan prioritas kegiatan ini didasarkan pada masalah yang dihadapi dilapangan atau diwilayah kegiatan.

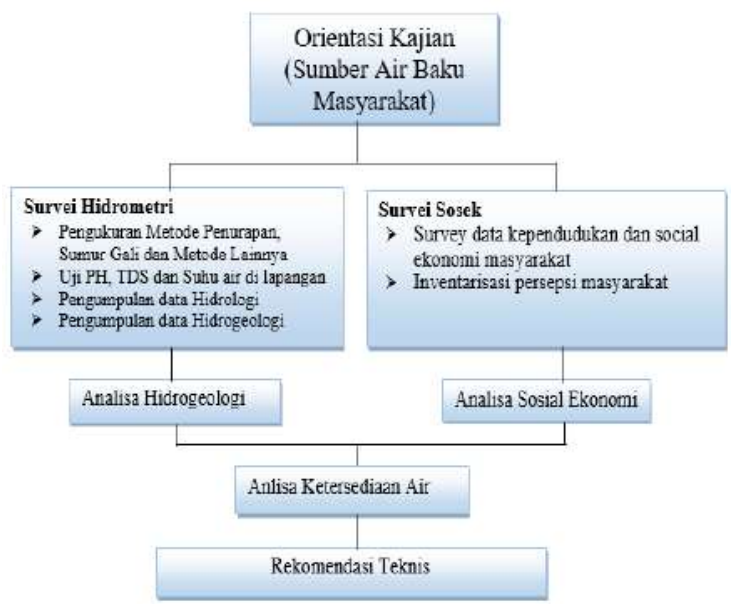

Gambar 1. Alur orientasi kegiatan

Alur penelitian diatas didasarkan pada dua aspek penting yaitu pada sumber air baku dan aspek sosial ekonomi. Kegitan survey ini melibatkan stekholder terkait, praktisi dan dosen dan mahasiswa teknik sipil unwira dalam studi kelayakan air baku bagi masyarakat pulau Palue. Dimana lebih diarahkan pada survey hidrometri dan sosial ekonomi masyarakat Pulau Palue.

\section{Waktu Pelaksanaan}

Rangkaian besar kegiatan ini berlangsung selama empat bulan pada bulan April - Juli 2018 yang melibatkan Balai Wilayah Sungai Nusa Tenggara II Satuan Kerja Pusat Air Tanah Air Baku, praktisi dan akademisi dalam hal ini dosen dan mahasiswa unwira. Keterlibatan aktif kegiatan ini hanya terfokus pada survey kelayakan air baku di pulau Palue yang dilaksanakan pada bulan April 2019.

\section{HASIL KEGIATAN} 1. Sumber Air Baku Hasil Penurapan
(Kondensasi)

Sumber air ini dilakukan dengan proses kondensasi/ pengembunan yang berasal dari uap panas yang keluar dari pori-pori dan rekahan batuan. Uap panas ini merupakan transfer panas secara konduksi menuju permukaan yang melewati lapisan batuan yang mengandung air (aquifer bebas), sehingga keluar uap hangat di permukaan melalui pori dan celah batuan. Batuan di daerah yang beruap, umumnya terdiri dari agglomerat, lapilli tuff dan lithic tuff yang berukuran kasar, belum terkonsolidasi baik, dan bersifat porous Metode pengambilan yaitu dengan menancapkan batang pipa bambu kedalam tanah kira-kira $0.6-2 \mathrm{~m}$, pipa bambu disambung dengan bambu mendatar. Uap panas yang keluar dari alam tanah, akan masuk kedalam tabung bambu dan kemudian mengalami pendinginan akibat suhu sekitar, sehingga berubah fase menjadi cair yang akan ditampung dalam suatu wadah. Ilustrasi dilapangan dapat dilihat pada Gambar 2.

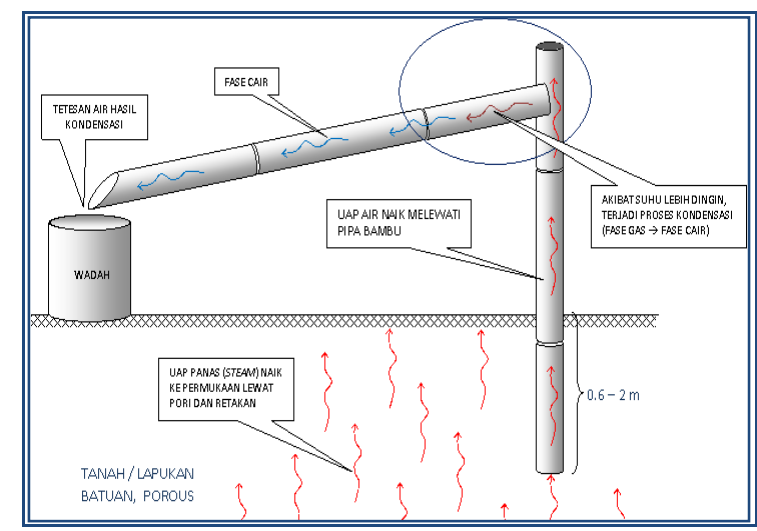

Gambar 2. Ilustrasi metode penurapan/ pengambilan air lewat proses kondensasi dengan pipa bambu

Menurut keterangan penduduk setempat, dalam waktu semalam ( \pm 12 jam) diperoleh \pm 10 lt air tiap satu bambu, dan air ini dapat langsung diminum. Pengambilan air dengan uap ini biasanya pada bulan Juli- Agustus, dimana cadangan air tampungan PAH sudah mulai habis. Proses pengambilan teknik kondensasi, dapat dilihat pada Gambar 3. Sedangkan debit air dan kualitas air berdasarkan survey lapangan, dapat dilihat pada Tabel1. 


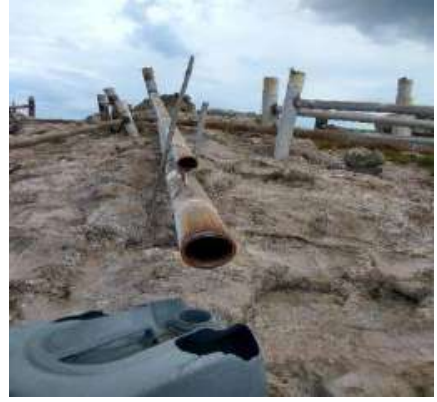

Gambar 3. Foto Teknik pengambilan air lewat proses kondensasi dengan pipa bamboo

Tabel 1. Hasil Inventarisai Dan Uji Fisik Air Hasil Kondensasi Uap Panas

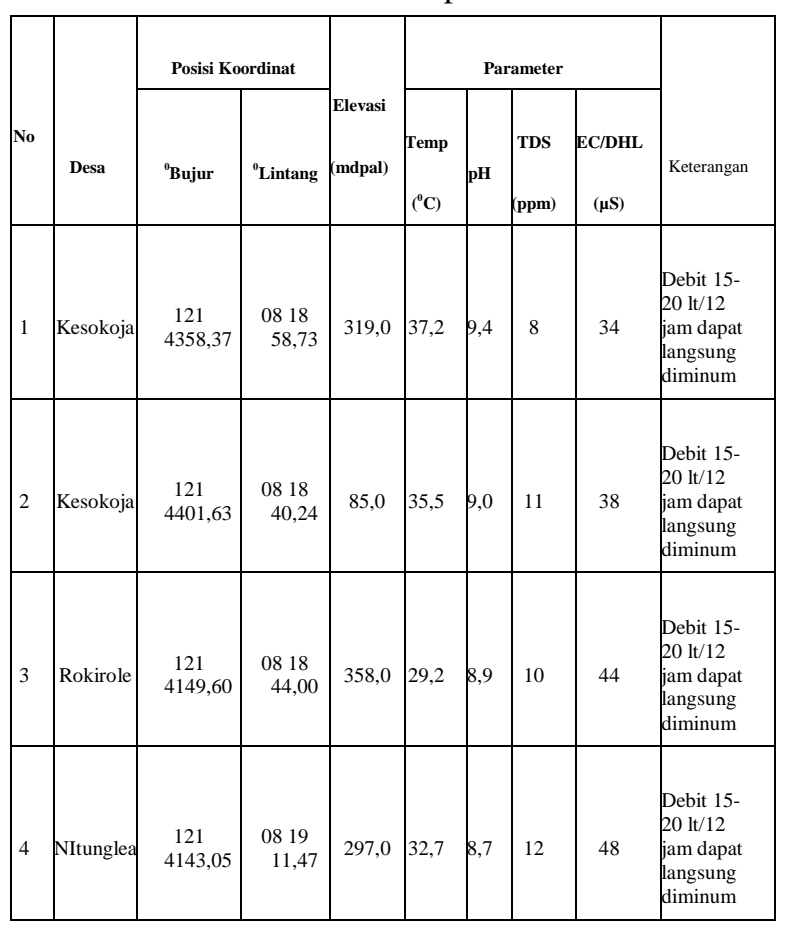

Sumber: [1]

2. Sumber Air Baku Hasil Penampungan Air Hujan (PAH)

PAH (Penampung Air Hujan) menjadi andalan utama dalam pemenuhan penyediaan air bersih seluruh masyarakat Palue, sehingga semua rumah memiliki sarana bak penampung air hujan ini. Bangunan PAH ini umumnya sudah permanen dengan ukuran bervariasi dan sebagian kecil menggunakan profil tank sebagai tambahan bak tampung. Kapasitas tampung Pah berkisar antara $18-36 \mathrm{~m}^{3}$ yang dimanfaatkan untuk air baku dan minum hingga bulan Juli, selanjutnya air
PAH hanya digunakan untuk air minum. Berdasarkan informasi dari Kecamatan Palue, jumlah PAH sudah lebih dari 750 buah yang tersebar diseluruh pulau. Kondisi PAH dipermukiman warga ditunjukkan pasa Gambar 4 dibawah ini.

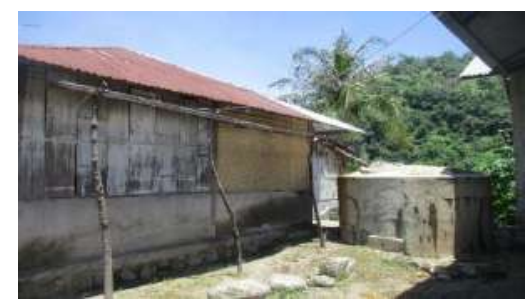

Gambar 4. Foto Teknik pengambilan air lewat proses kondensasi dengan pipa bamboo

Hasil uji kualitas air di lapangan yang diambil dari beberapa bak tampung pada beberapa desa, air dalam bak tampung ini mempunyai PH 9.4 - 10.4, dengan jumlah padatan terlarut (TDS) antara 45 ppm - 48 ppm, tidak berbau dan tawar. Hasil selengkapnya dapat dilihat dalam Table 2 berikut.

Tabel 2 . Hasil Inventarisai Dan Uji Fisik Air Hasil Kondensasi Uap Panas

\begin{tabular}{|c|c|c|c|c|c|c|c|c|c|}
\hline \multirow{2}{*}{$\begin{array}{l}\mathbf{N} \\
\mathbf{o}\end{array}$} & \multirow{2}{*}{$\begin{array}{l}\text { PAH } \\
\text { Desa }\end{array}$} & \multicolumn{2}{|c|}{$\begin{array}{c}\text { Posisi } \\
\text { Koordinat }\end{array}$} & \multirow{2}{*}{ (mdpal) } & \multicolumn{4}{|c|}{ Parameter } & \multirow[b]{2}{*}{$\begin{array}{c}\text { Salinitas } \\
(\%)\end{array}$} \\
\hline & & ${ }^{0}$ Bujur & ${ }^{0}$ Lintang & & $\begin{array}{r}\text { Tem } \\
\mathbf{p} \\
\left({ }^{0} \mathrm{C}\right)\end{array}$ & pH & $\begin{array}{l}\text { TDS } \\
\text { (ppm) }\end{array}$ & $\begin{array}{c}\text { EC/DHL } \\
(\mu \mathrm{S})\end{array}$ & \\
\hline 1 & \begin{tabular}{|c|} 
PAH \\
Reruwairere
\end{tabular} & $\begin{array}{c}121 \\
4344, \\
75\end{array}$ & $\begin{array}{c}0818 \\
03.40\end{array}$ & 30,0 & 30,9 & $\begin{array}{r}20, \\
2\end{array}$ & 46 & 93 & $\begin{array}{l}\text { Rasa } \\
\text { tawar }\end{array}$ \\
\hline 2 & $\begin{array}{c}\text { PAH } \\
\text { Maluriwu }\end{array}$ & $\begin{array}{c}121 \\
4327, \\
32\end{array}$ & $\begin{array}{c}0817 \\
57.24\end{array}$ & 19,0 & 30,9 & $\begin{array}{r}10 \\
3\end{array}$ & 47 & 93 & $\begin{array}{l}\text { Rasa } \\
\text { tawar }\end{array}$ \\
\hline 3 & $\begin{array}{c}\text { PAH } \\
\text { Nitunglea }\end{array}$ & $\begin{array}{c}121 \\
4116 \\
00\end{array}$ & $\begin{array}{c}0819 \\
22.19\end{array}$ & 320,0 & 31,0 & $\begin{array}{r}10 \\
4\end{array}$ & 48 & 97 & $\begin{array}{l}\text { Rasa } \\
\text { tawar }\end{array}$ \\
\hline 4 & $\begin{array}{c}\text { PAH } \\
\text { Rokirole }\end{array}$ & $\begin{array}{c}121 \\
4149, \\
80\end{array}$ & $\begin{array}{c}0818 \\
43.01\end{array}$ & 301,0 & 30,7 & $\begin{array}{r}10, \\
5\end{array}$ & 45 & 91 & $\begin{array}{l}\text { Rasa } \\
\text { tawar }\end{array}$ \\
\hline 5 & $\begin{array}{l}\text { PAH } \\
\text { Lidi }\end{array}$ & $\begin{array}{c}121 \\
4424, \\
70\end{array}$ & $\begin{array}{c}0820 \\
29.56\end{array}$ & 89,0 & 30,7 & $\begin{array}{r}10, \\
4\end{array}$ & 46 & 92 & $\begin{array}{l}\text { Rasa } \\
\text { tawar }\end{array}$ \\
\hline
\end{tabular}

Sumber: [1] 


\section{Kondisi Sosial Ekonomi}

Kecamatan Palue terdiri dari 8 Desa dan 24 dusun, dengan jumlah penduduk berdasarkan data kecamatan tahun 2017 adalah $2.661 \mathrm{kk}$ dengan total 9.929 jiwa dengan populasi pedesanya ditunjukkan pada Gambar 4.

Data kependudukan Kecamatan Palue menunjukkan kepadatan seluruh pulau hanya 2 jiwa per hektar, dengan penyebaran yang tidak merata, dimana di desa Tuanggeo, Rokirole dan Lidi mempunyai kepadatan terbesar, yaitu 4 jiwa/Ha, sedangkan desa Kesokoja kepadatan terkecil, yaitu $1 \mathrm{jiwa} / \mathrm{Ha}$ ditunjukkan pada Tabel 3 .

Gambar 4.. Jumlah Penduduk Menurut Desa Di Kecamatan Palue Tahun 2018

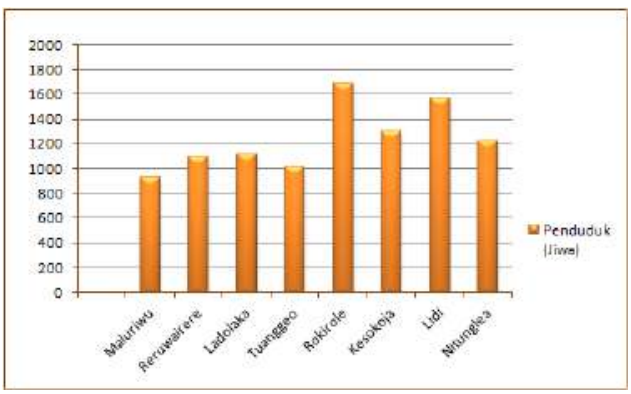

Sumber : [2]

Tabel 3. Data Kepadatan Penduduk Tiap Desa di Kecamatan Palue 2017

\begin{tabular}{|l|l|l|l|l|}
\hline No & Nama & $\begin{array}{l}\text { Jumlah } \\
\text { Penduduk } \\
\text { (Jiwa) }\end{array}$ & $\begin{array}{l}\text { Luas } \\
\text { Wilayah } \\
\text { (Ha) }\end{array}$ & $\begin{array}{l}\text { Kepadatan } \\
(\text { Jiwa/Ha) }\end{array}$ \\
\hline 1 & Maluriwu & 924 & 311,61 & 3 \\
\hline 2 & Reruwairere & 1094 & 371,52 & 3 \\
\hline 3 & Ladolaka & 1114 & 500,33 & 2 \\
\hline 4 & Tuanggeo & 1014 & 265,38 & 4 \\
\hline 5 & Rokirole & 1687 & 391,88 & 4 \\
\hline 6 & Kesokoja & 1301 & 1068,71 & 1 \\
\hline
\end{tabular}

\begin{tabular}{|l|l|l|l|l|}
\hline 7 & Lidi & 1568 & 356,84 & 4 \\
\hline 8 & Nitunglea & 1227 & 712,20 & 2 \\
\hline JUMLAH & 9929 & 3987,47 & 2 \\
\hline
\end{tabular}

Sumber: [2]

Masyarakat Palue mayoritas beragama Katolik, umumnya sebagai nelayan dan sebagian berladang dan berkebun dengan total luas lahan yang diusahakan adalah $2271.5 \mathrm{Ha}$ atau $57.10 \%$ dari luas seluruh pulau. Adapun perincian luasan tanam adalah sebagai berikut [2]:

$$
\begin{array}{ll}
\text { Jagung } & =301.0 \mathrm{ha} \\
\text { Kacang Hijau } & =121.0 \mathrm{ha} \\
\text { Ubi Kayu } & =83.5 \mathrm{ha} \\
\text { Sayuran } & =35.0 \mathrm{ha}
\end{array}
$$

Hasil lainnya yaitu kelapa/kopra, mete dan kakao yang cukup banyak ditaman masyarakat. Berdasarkan data kabupaten Sikka 2016/2017, luas lahan dan jumlah produksi tanaman perkebunan di Pulau Palue adalah sebagai berikut

$$
\begin{array}{lll}
\text { Kemiri } & =9.0 \text { ha }(2 \text { ton }) \\
\text { Kelapa } & =575.0 \text { ha }(282 \text { ton }) \\
\text { Jambu Mete } & =761.0 \text { ha }(211 \text { ton }) \\
\text { Kakao } & =386.0 \text { ha }(90 \text { ton })
\end{array}
$$

\section{EVALUASI KEGIATAN}

Analisis kebutuhan air bersih menggunakan pemakaian air rata-rata 60 liter/orang/hari (rata-rata pemakaian air di wilayah pedesaan sebesar 60 liter/orang/hari dengan asumsi pemakaian air untuk mandi dan keperluan lain sebesar $50 \%)$ [3].

Mengacu pada jumlah pemakaian air di daerah perdesaan, maka dapat 
dihitung volume kebutuhan air bagi masyarakat setiap Desa di Kecamatan Palue berdasarkan data jumlah penduduk kecamatan Palue tahun 2018. Hasil perhitungan kebutuhan air masyarakat ditampilkan pada Tabel 4.

Tabel 4. Data Kepadatan Penduduk Tiap Desa di Kecamatan Palue 2017

\begin{tabular}{|c|c|c|c|c|}
\hline \multirow[b]{2}{*}{ No } & \multirow[b]{2}{*}{ Desa } & \multirow{2}{*}{$\begin{array}{l}\text { Total } \\
\text { (Jiwa) }\end{array}$} & \multicolumn{2}{|c|}{ Kebutuhan Air } \\
\hline & & & $\begin{array}{l}\text { Hari } \\
\text { (m3/hari) }\end{array}$ & $\begin{array}{l}\text { Pertahun } \\
\text { (m3/hari) }\end{array}$ \\
\hline 1 & Maluriwu & 924 & 27,72 & $10.117,80$ \\
\hline 2 & Reruwairere & 1.094 & 32,70 & $11.935,50$ \\
\hline 3 & Ladolaka & 1.114 & 33,42 & $12.198,30$ \\
\hline 4 & Tuanggeo & 1.014 & 30,42 & $11.103,30$ \\
\hline 5 & Rokirole & 1.687 & 50,61 & $18.472,65$ \\
\hline 6 & Kesokoja & 1.301 & 39,87 & $14.245,95$ \\
\hline 7 & Lidi & 1.568 & 47,04 & $17.169,60$ \\
\hline 8 & Nitunglea & 1.227 & 36,87 & $13.435,65$ \\
\hline Tot & & 9.925 & 297,75 & $108.678,75$ \\
\hline
\end{tabular}

Sumber: [1]

Pada Tabel 4 dapat dijelaskan bahwa jumlah pemakai air untuk keseluruhan masyarakat Pulau Palue adalah sebesar 297,75 m3/hari dan 108.678,75 m3/tahun. Rincian kebutuhan besaran kebutuhan air perdesa tergambar dalam diagram batang pada Gambar 6 berikut.

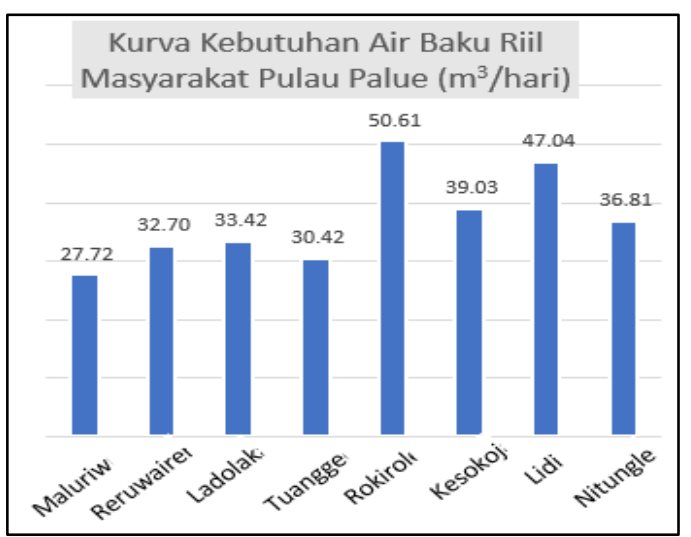

Gambar 5. Jumlah Penduduk Menurut Desa Di Kecamatan Palue Tahun 2017

Keberadaan masyarakat Palue tidak bisa lepas dari aktivitas G. Rokatenda yang beberapa tahun belakangan menunjukkan aktifitas yang meningkat. Alasan kuat masyarakat Palue enggan direlokasi karena rasa kecintaan mereka terhadap tanah leluhur yang sudah mendiami pulau itu sangat lama, sehingga walaupun kekurangan air bersih dan adanya aktifitas gunung api yang mengancam, masyarakat tetap bertahan.

Pemenuhan akan air baku, seluruh pulau mengandalkan air hujan yang ditampung dalam bak tampung (PAH), sehingga setiap rumah memiliki bak tampung sendiri, baik yang permanen maupun dari fiber profil tank [1].

Selain air hujan, di setiap desa memiliki sumber-sumber air lain yang jumlahnya sangat terbatas, misalnya di desa Rokirole, Nitunglea dan Kesokoja terdapat ladang-ladang uap panas yang dengan metode penyulingan sederhana bisa mendapatkan air minum walaupun kurang mencukupi. Di Tuanggeo sering memanfaatkan air dari bonggol pohon pisang untuk pemenuhan air minum. Sedangkan di Maluriwu, Reruwairere dan Ladolaka memanfaatkan air sumur dangkal yang payau di beberapa tempat di daerah pesisir [1]. 


\section{REKOMENDASI TEKNIK}

Berdasarkan data yang diperoleh pada saat melakukan survey di lokasi kegiatan dan hasil evaluasi, rekomendasi teknik yang disarankan antara lain

1) Masyarakat diharapkan melakukan pembersihan secara rutin terhadap komponen PAH maupun Pipa bambu sumber air hasil kondensasi.

2) Pemerintah, Lembaga Swadaya Masyarakat dan Pihak-pihak lain yang terkait diharapkan melakukan studi lanjutan mengenai potensi sumber air baku di Pulau Palue.

3) Apabilah sumber air yang mungkin diperoleh berasal dari dalam tanah, maka disarankan untuk tidak melakukan eksploitasi dengan kedalaman yang ekstrim.

\section{SARAN}

Pemenuhan kebutuhan akan air bersih adalah keharusan dalam keberlangsungan hidup. Kerinduan untuk memperoleh air baku dengan standar unsur kesehatan minimal, sangat dirindukan oleh masyarakat Pulau Palue. Oleh karena itu dukungan para pihak dalam menemukan potensi sumber air hingga pada tahap eksploitasi, sangat diharapkan untuk mengantisipasi masalah air bersih di daerah tersebut.

\section{UCAPAN TERIMA KASIH}

Terima kasih disampaikan kepada masyarakat Pulau Palue, Balai Wilayah Sungai Nusa Tenggara II Satuan Kerja P2AT, Pihak Konsultan Teknik dan semua pihak yang ikut membantu dalam kegiatan "Studi Potensi dan Kelayakan Air Baku Pulau Palue" tahun 2018. Semoga keterlibatan kami dirindukan dalam kegiatan selanjutnya.
DAFTAR PUSTAKA

[1] Laporan akhir Kencana Adya Daniswara Konsultan, "Studi Potensi dan Kelayakan Air Baku Pulau Palue," PT. KAD, Kupang, 2018.

[2] Badan Pusat Statistik, SIkka Dalam Angka 2018, Maumere: BPS, 2018.

[3] Lampiran II Peraturan Menteri Pekerjaan Umum, Petunjuk Teknis Standar Pelayanan Minimal Bidang Pekerjaan Umum dan Penataan Ruang Nomor 14/PRT/M/2010, Jakarta: Kementrian PUPR, 25 Oktober 2010.

[4] UU no 7, Undang-Undang tentang Sumber Daya Air, Jakarta, 2004. 